\title{
HILGARDIA
}

A Journal of Agricultural Science Published by the California Agricultural Experiment Station

\section{SIMI, A PROCESSING TOMATO RESISTANT TO VERTICILLIUM AND FUSARIUM WILTS}

J. W. LESLEY, JOHN T. MIDDLETON, and C. D. MCCARTY 
This paper reports on the recent development of a new tomato variety, the Simi, which is resistant to verticillium and fusarium wilts and is recommended for trial on the southern California coastal plain and valleys near the coast. It is less fruitful than Pearson in the interior valleys. A good solid tomato with only a moderate-sized white core, Simi is especially promising for processing into paste and other concentrates on account of its fleshiness and deep red color.

Symptoms of the two wilt diseases, methods of experimental plant infection, evidence of occurrence of verticillium strains, and a description of the wilt-resistant Simi tomato are presented.

See outside back cover for Table of Contents. 


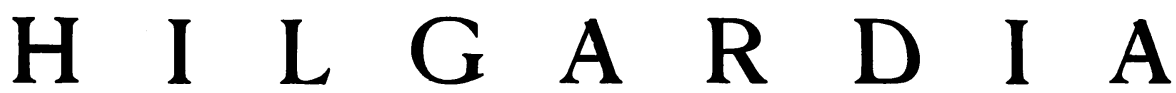

A Journal of Agricultural Science Published by the California Agricultural Experiment Station

\section{SIMI, A PROCESSING TOMATO RESISTANT TO VERTICILLIUM AND FUSARIUM WILTS}

\section{J. W. LESLEY, JOHN T. MIDDLETON, ${ }^{3}$ and C. D. MCCARTY ${ }^{4}$}

\section{INTRODUCTION}

THERE ARE TWo FUnGus wiLts of tomato which cause serious losses in California. The most common is verticillium wilt, caused by the fungus Verticillium albo-atrum R. and B., which is distributed throughout coastal and inland tomato growing areas. The other, fusarium wilt, caused by the fungus Fusarium oxysporum f. lycopersici Snyder and Hansen, is not as common as verticillium wilt, and although found in both coastal and inland areas is usually most damaging in the warmer inland tomato districts. Verticillium wilt is more troublesome than fusarium wilt not only because of its wider geographic distribution and the variety of plants affected, but because of the difficulty of controlling it by means of wilt-resistant varieties. The fungus causing fusarium wilt affects tomatoes only.

The great popularity of the Pearson tomato in California is due in part to its tolerance to these wilt diseases. Also, Pearson is remarkably fruitful from the coast to the interior valleys, where low night temperatures seriously limit the fruitfulness of very large fruited varieties such as Santa Clara and Essar.

A new variety, the Simi tomato-named after the town of Simi, Ventura County, California, adjacent to the coastal range where it was first grown successfully - appears to equal or exceed Pearson in yield on verticilliuminfested soils of the coastal valleys and plain. In the interior valleys Pearson is more fruitful. The Simi variety is considered promising under southern California coastal conditions, especially for processing into concentrated forms. In California in 1941-45, 63 per cent of the tomato tonnage produced was made into paste, sauces, soups, and puree. (Fisher, 1947.) ${ }^{5}$

This report contains a brief account of the two wilt diseases and of the procedure of experimental plant infection, presents evidence of the occurrence of strains of $V$. albo-atrum, and describes the development and characteristics of the wilt-resistant Simi tomato.

${ }^{1}$ Paper No. 681, University of California Citrus Experiment Station, Riverside, California. Submitted for publication June 8, 1950.

${ }^{2}$ Geneticist in the Experiment Station, Riverside.

${ }^{3}$ Associate Plant Pathologist in the Experiment Station, Riverside.

${ }^{4}$ Senior Laboratory Technician, Riverside.

${ }^{5}$ See "Literature Cited" for citations, referred to in the text by author and date. 


\section{THE DISEASES}

Tomatoes affected with either verticillium or fusarium wilt usually show some wilting, yellowing, and dropping of leaves. Although the symptoms of the two diseases are very similar there is generally more leaf wilt and stunting in fusarium-infected plants than in verticillium-infected plants. The loss of the old, lower, crown leaves most frequently occurs in verticillium-infected plants, concurrently with fruit ripening. The exposed tomatoes usually sunburn, and discolor. A brown discoloration of the stem tissue of both verticillium- and fusarium-infected plants is usually evident when stems are cut or broken open. Crop losses result from poor yields due to abnormal plant growth, fruit disfiguration due to irregular growth, and discoloration due to sunburn.

Symptoms of both wilt diseases are more manifest in warm weather than in cool. It is not uncommon for apparently healthy tomato plants to wilt and deteriorate suddenly with the advent of warm weather following a cool growing period.

The two wilt diseases cannot be definitely distinguished on appearance alone. Identification must be based on the specific determination of the fungus present in the affected tissues.

\section{Infection of Tomato Plants}

Selection of resistant material depends in part upon a method of plant infection that is uniform and reproducible. The procedure and technique described below appear to have satisfied these requirements.

Pure cultures of pathogenic strains of the fungi were maintained on suitable culture media. Separate water suspensions of the fungus spores were made of each fungus and placed in a glass vessel. Seedling tomato plants were removed from the pots of sand in which they were grown and their roots rinsed in water. Excess water was removed and the roots then momentarily immersed in the spore suspension. Dipped plants were immediately transplanted to sterilized soil.

The sterilized soil used for the verticillium trials was contained in metal cans which were subsequently suspended in a water bath, which maintained the root area at approximately $70^{\circ} \mathrm{F}$. Plants were grown two to three weeks at this temperature, permitting adequate plant growth and optimum conditions for fungus infection. Selections for resistance were made from these cans for future field testing.

The sterilized soil used for the fusarium trials was contained in wooden flats. These were placed on benches in a glasshouse in which the air temperature was about $80^{\circ} \mathrm{F}$, permitting development of fusarium wilt. Selections for resistance were made two to three weeks later for future field trials.

\section{Occurrence of Strains in Verticillium albo-atrum}

A large number of verticillium-inoculated seedling tomato plants which appeared to be resistant were removed from the soil cans after three weeks and examined for the presence of the causal fungus. Plants with shortened internodes and small terminal leaves showing slight unilateral curvature 
were usually found to harbor the fungus. A number of inoculated plants were free from the fungus at the time of examination. They were transplanted to flats of soil, and when large enough, later planted in the field. These plants were observed throughout the growing season. Stem samples were collected at harvest time and Verticillium albo-atrum was observed in a few instances. These isolates proved to be pathogenic to Simi seedlings upon inoculation.

The initial freedom from the causal fungus is attributed to plant resistance and the failure of the particular strain of the fungus used to develop within the tomato seedling. Subsequent isolation of Verticillium albo-atrum from the originally fungus-free plant is attributed to the entrance of strains of $V$. albo-atrum existing in the field soil used. These particular strains were not only able to enter but to develop within the plant resistant to the original fungus strains employed in the seedling inoculation trials.

Resistant tomato varieties respond to the strains used usually by a slight shortening of the internodes, little or no vascular discoloration, some wilting, and the absence of unilateral leaf curvature, whereas susceptible varieties show considerable shortening of the internodes, obvious vascular discoloration, wilting, and conspicuous unilateral leaf curvature. The presence of a variety of fungus strains may explain the apparent variability of resistance in certain tomato varieties.

Additional evidence is accumulating which demonstrates the existence of strains of Verticillium albo-atrum in California. Snyder, Hansen, and Wilhelm (1950) demonstrated that isolates of $V$. albo-atrum from Brussels sprouts, cabbage, stock, and nightshade are unable to infect Bonny Best tomato, but that isolates from olive and blackberry cause severe wilting in tomato.

Since there are strains of Verticillium albo-atrum which vary in their pathogenicity to tomatoes, evidently the fungus is mutable and of changeable habit. On this account, a genetically very uniform tomato variety seems undesirable. An acceptable verticillium-resistant tomato should possess sufficient plasticity to accommodate the varying strains of the causal fungus. Control of the fungus population is not yet feasible. Genetically uniform tomato varieties may serve little useful purpose for they are not likely to become adapted to local environments and fungus strain populations.

\section{DEVELOPMENT OF THE VARIETY}

In 1928 a wilt-resistant variety named Riverside was introduced (Shapovalov and Lesley, 1940). The fruit is regular in shape, only slightly oblate but rather small. This was crossed with N.D. 216-2-3, an extremely prolific variety with a small, determinate or "self-pruning" vine and large irregular fruit, obtained from the North Dakota Agricultural Experiment Station. In 1940 the $\mathrm{F}_{1}$ family, obtained by crossing a Riverside $\times$ N.D. 216-2-3 hybrid to Riverside, was artificially inoculated with a culture of Verticillium albo-atrum and Fusarium oxysporum f. lycopersici. An $\mathrm{F}_{1}$ plant was selected and selfing was continued for six more generations, of which each successive family was either artificially inoculated with the wilt fungi or was planted in heavily infested soil. A number of single plants were selected in each generation. Segregation of genes for resistance to fusarium was evident in the 
earlier generations. Continued selfing and single plant selection led to a great reduction in the amount of radial or star cracking, an increase in fruit size, and probably a reduction in vegetative vigor and a later maturity.

Twelve $\mathrm{F}_{6}$ populations were planted, each consisting of 20 plants and all originally from the same $\mathrm{F}_{3}$ plant. They varied in fruit size and shape and in refractive index of juice, but were in many respects similar. One of them, 44.6, was selected because it had the best combination of characters, including the largest fruit size, with the highest refractive index of juice, and was second best in regularity of fruit shape. Another $\mathrm{F}_{6}$ family had fruit that was less oblate, more regular in shape and containing less white core, while the fruit was less fleshy and lower in refractive index. From a selected plant in 44.6, $\mathrm{F}_{7}$ was grown and from it an $\mathrm{F}_{8}$ population was used to produce seed. An elite seed stock was saved from eight $\mathrm{F}_{8}$ selected plants and the rest was used for distribution for trial in small quantities under the name Simi. A survey of commercial and small experimental plantings in southern California in 1949 indicates that a reasonable amount of uniformity may be expected from pure seed of the Simi variety.

\section{General Characteristics}

Simi differs from Pearson in having an indeterminate vine. At Moorpark, California, with very little irrigation the vine was quite short, but near Artesia, California, with abundant, perhaps excessive irrigation and fertilization, it was so long as to interfere with picking and loading. A distinctive characteristic of Simi is the uniform green color of the immature fruit. Fruit of this type develops a pale green color, indicative of incipient reddening, several days earlier than the usual nonuniform green type. The flesh color of Simi develops slowly but when fully ripe is deep red and the proportion of hard core is smaller than in Pearson. The fruit is extremely fleshy. When used either fresh or processed the quality is excellent. The first fruits to ripen, especially in coastal regions, are very irregular in shape and unsuitable for commercial canning, but later fruits are less irregular. At Riverside the fruit was more regular.

The shape index, or ratio of the mean of two transverse diameters to the polar diameter or length, was measured in samples harvested in September at Riverside, Simi, and Artesia, California. At Riverside, furthest from the coast, with a light erop, the ratio in 1946 was 1.25 , and in 1949, 1.31. At Simi, nearer the coast, with a good crop, it was 1.34 in 1946; at Los Alamitos, much nearer the coast and with a heavy crop, 1.47. The difference between the ratios at Artesia and Riverside in 1949 is statistically significant at the 5 per cent level. Apparently the fruit is more oblate with increasing proximity to the coast.

\section{Horticultural Description}

A description of the Simi variety may be helpful to growers and processors for identifying it and maintaining a seed stock of the proper type. (Figures 1,2 .)

Adaptability and use. Productive in southern California on the coastal plain and in the Simi Valley but less productive further from the coast. Probably not suitable for growth in central California. Recommended for fresh 


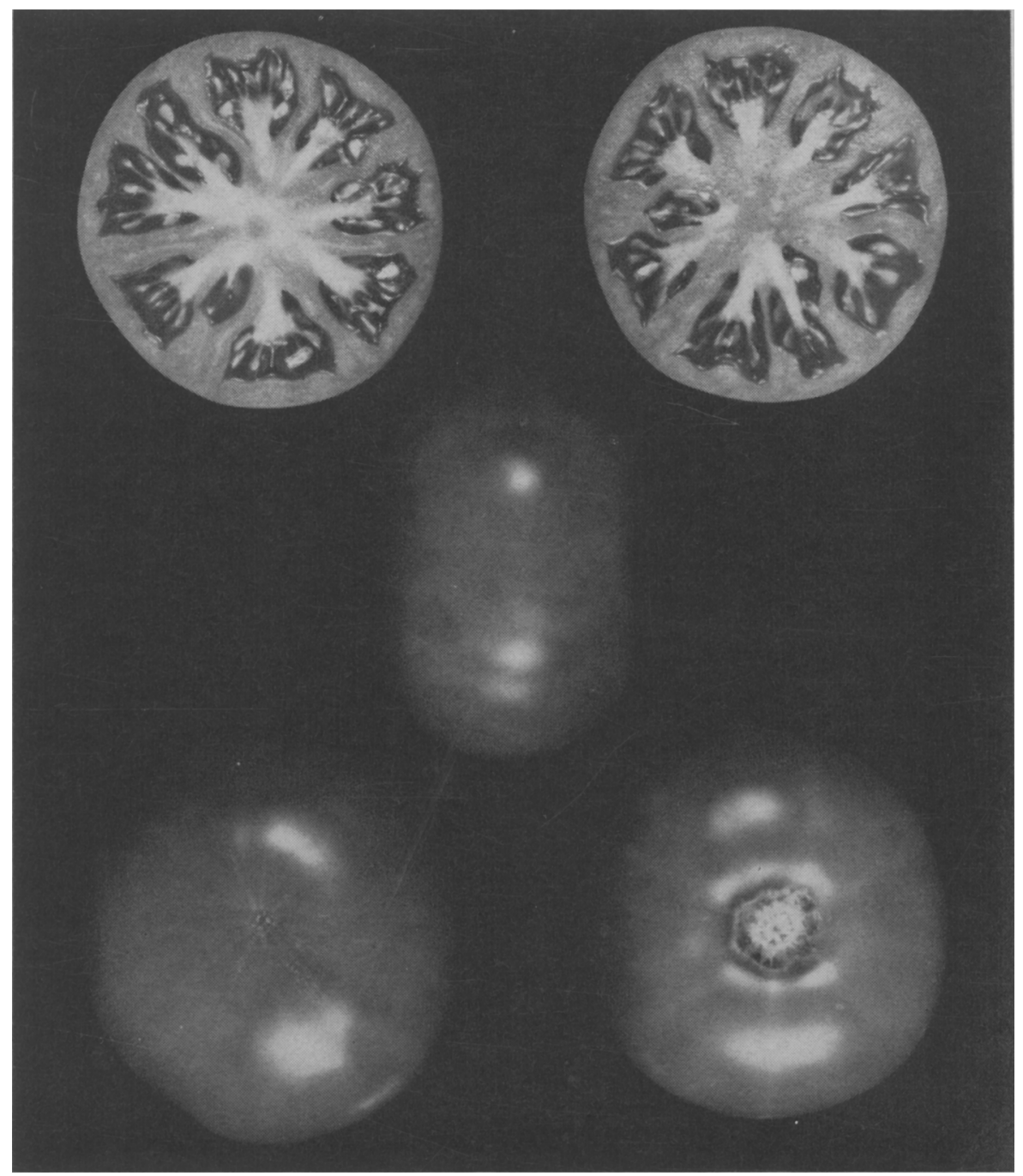

Fig. 1. Fruit of the Simi tomato.

use or processing when irregularity of fruit shape is unimportant. Resistant to verticillium and fusarium wilts.

Season. Matures late; in southern California, late August to early September.

Plant. Vine at fruit maturity procumbent, sometimes too open ; indeterminate but if irrigated sparingly, short, and some branches determinate. Branches usually 9 to 12 .

Flowers. Two to eight per inflorescence. About three nodes between inflorescences. Supernumerary sepals, petals, carpels, and stamens regularly occur, in numbers ranging from five to ten or more. 
Fruit, exterior. Immature fruit uniform green. Mature fruit weighs usually 130 to over $200 \mathrm{~g}$. Shape oblate; mean equatorial diameter $\div$ polar diameter, 1.25 to 1.47. Earliest fruits often corrugated and with irregular basin. Radial cracks few, circular cracks few to many. Skin yellow, thick, tough. Keeping quality, good.

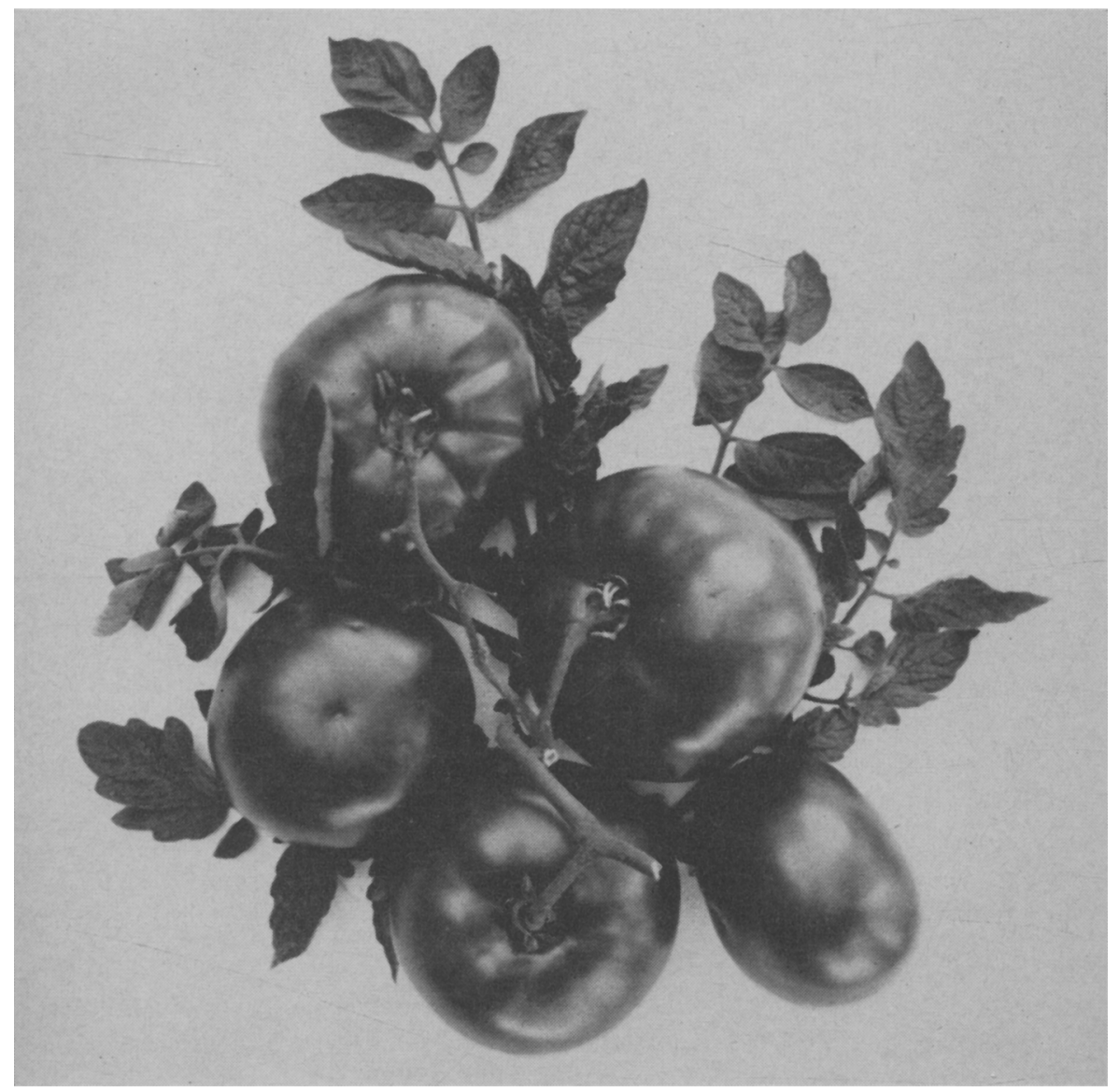

Fig. 2. A group of Simi fruit.

Fruit, interior. Outer wall thick, septa thick, very fleshy. Loculi small, numbering 9 to 19 , mean 14 . Fleshy center usually present; white core medium in proportion, less in fully ripe fruits. Seeds few. Flesh color deep red when fully ripe.

\section{Composition}

Some composition tests of the Simi, Pearson and San Marzano tomatoes were made in an attempt to determine if any real differences exist between these varieties.

Total solids. The percentage of total solids was estimated individually from the refractive index and by the use of the table in the National Canners Asso- 
ciation Report No. 10566 C (1947), while direct determinations were made in a drying oven.

In preparing the samples for testing, ten fruits from each variety were picked at random, washed, dried, and quartered. Alternate quarters of each fruit were blended together in a Waring blendor for five minutes. The samples were then centrifuged, ten minutes being enough in most cases to separate the pulp. Duplicate readings were made with an American Optical Company refractometer on the cleared supernate.

TABLE 1
PER CENT TOTAL SOLIDS OF TEN-FRUIT SAMPLES BASED ON REFRACTOMETER READINGS AND TABLES IN NATIONAL CANNERS ASSOCIATION RESEARCH LABORATORY REPORT NO. $10566 \mathrm{C}$

\begin{tabular}{|c|c|c|c|}
\hline \multirow{2}{*}{ Place } & \multirow{2}{*}{ Date } & \multicolumn{2}{|c|}{ Per cent total solids } \\
\hline & & Simi & Pearson \\
\hline Riverside.......... & $8 / 26 / 49$ & 6.35 & 5.85 \\
\hline Riverside $\ldots \ldots \ldots \ldots \ldots \ldots \ldots$ & $8 / 31 / 49$ & 6.20 & 6.20 \\
\hline Riverside.... & $9 / 2 / 49$ & 5.70 & 5.70 \\
\hline Riverside... & $9 / 12 / 49$ & 6.10 & 6.50 \\
\hline Riverside.... & $9 / 17 / 49$ & 6.15 & 6.10 \\
\hline Chino......... & $9 / 7 / 49$ & 6.15 & 6.15 \\
\hline Chino........... & $10 / 12 / 49$ & 5.80 & 5.80 \\
\hline Los Alamitos... & $9 / 16 / 49$ & 5.90 & 5.60 \\
\hline Los Alamitos.. & $9 / 19 / 49$ & 6.0 & 5.85 \\
\hline Costa Mesa.. & $9 / 27 / 49$ & 8.0 & 7.65 \\
\hline Cypress...... & $10 / 4 / 50$ & 6.31 & $7.14^{1}$ \\
\hline Cypress, large fruit.. & $10 / 4 / 50$ & 6.78 & 7.092 \\
\hline Cypress, small fruit . . . . . . . . . & $10 / 4 / 50$ & $7.74^{3}$ & 7.10 \\
\hline
\end{tabular}

\footnotetext{
1 Significantly higher than Simi at the 1 per cent level.

2 Significantly higher than large Simi fruit at the 5 per cent level.

2 Significantly higher than large Simi fruit at the 5 per cent level.
3 Sign ificantly higher than large Simi fruit and the small Pearson fruit at the 1 per cent level.
}

In 1944, refractometer readings indicated that Simi stock selected for propagation had a total solids content of approximately 6 per cent as compared to a total solids content of 5 per cent for the Pearson samples tested that year. In 1948, the Simi and Pearson samples tested came from plants grown at Riverside and Chino, respectively. The Simi tomato contained approximately 7 per cent and Pearson approximately 6 per cent. In 1949, samples of Simi and Pearson were taken at Riverside and Chino in the inland area, and Los Alamitos and Costa Mesa in the coastal plain area. The Simi contained a mean of 6.2 per cent total solids as against 6.1 for the Pearson, and was as high as or higher than the Pearson in nine out of ten samples (table 1). The difference between the means was not statistically significant at the 5 per cent level but may indicate a slightly higher solids content in Simi. Samples of both varieties grown near the coast gave higher values than those grown further inland; the same relation was reported by Saywell and Cruess (1932).

In 1950, total solids were determined from the refractive index of ten samples, each containing ten fruits of Simi and of Pearson. The mean for 
Pearson based on the refractive index was 7.1, and for Simi, 6.3. To test the relation between total solids and fruit size, refractometer tests were made with large and small fruits of Simi and Pearson. In Pearson the large and small fruits came from the same vines. Ten samples of ten fruits, in which the average weight per fruit was $139.3 \mathrm{~g}$, gave a mean of 7.1 per cent total solids; the same number of samples in which the average weight per fruit was $58.5 \mathrm{~g}$ also gave 7.1 per cent. Due to the inability to procure both large and small fruit from the same vines, fruit was picked at random for the Simi samples. The large fruit samples which averaged $209.4 \mathrm{~g}$ per fruit gave a mean of 6.8 and standard deviation of .29 per cent solids, while the small fruit samples averaging $68.5 \mathrm{~g}$ per fruit gave a mean of 7.7 and standard deviation of 1.68 per cent solids. In the small fruit samples, solids content

TABLE 2

PER CENT OF TOTAL SOLIDS BY DIRECT DETERMINATION. SAMPLES DRIED IN A VACUUM OVEN AT $70^{\circ} \mathrm{C}$

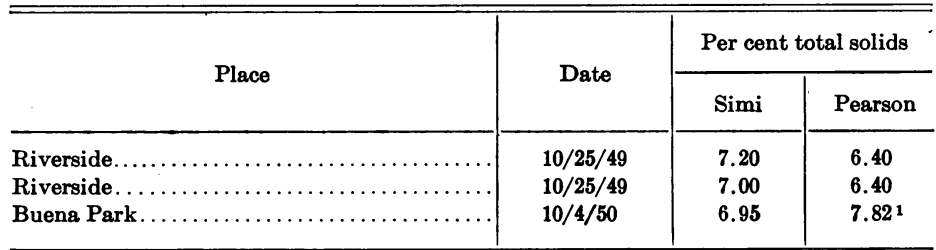
level.

${ }^{1}$ Means of 10 samples. Pearson was significantly higher than Simi at the 5 per cent

ranged from 10.0 per cent, a remarkably high value, to a low of 6.0 per cent, while the range of the samples containing large fruit ran from only 7.4 to 6.6 per cent. The small fruit, some of which came from vines stunted by the high salts content of the soil, showed a high degree of variation in the solids content.

At the close of the 1949 season direct determinations of total solids content were carried out. After $181 / 2$ hours at $70^{\circ} \mathrm{C}$ in an incubating oven to evaporate the greater part of the moisture present, the samples were placed in a vacuum oven at $70^{\circ} \mathrm{C}$ for 40 hours. The two Simi samples contained 7.0 and 7.2 per cent total solids, and the two Pearson samples contained 6.4 per cent total solids. These results are not conclusive, but, like the refractometer readings, indicate that Simi is slightly higher than Pearson in total solids (table 2). Direct determinations were also made in 1950 with ten samples each of ten fruits of Simi and Pearson. The mean for Pearson was 7.8 per cent and for Simi 7.0 per cent. All direct determinations suggest a much higher total solids content, especially in Simi, than those estimated from the refractive index. The N.C.A. report (1947) states that in tomatoes total solids content cannot be determined very accurately from the refractive index by the use of the conversion table. In 1949, San Marzano, a variety generally credited with a high content, was estimated to contain only 5.9 per cent total solids by the indirect method.

The total solids determination by both methods in 1950 indicated that Pearson was higher than Simi, whereas in 1948 and 1949 they suggested the 
opposite. Apparently these two varieties reacted differently to environmental conditions, such as climate and cultivation, so that no consistent difference in solids content could be found.

$\mathrm{pH}$. Determinations on $\mathrm{pH}$ were made with a Beckman glass electrode $\mathrm{pH}$ meter. Readings were taken on the supernate of tomato samples after ten minutes of centrifuging. The average $\mathrm{pH}$ of Pearson was less than that of Simi but the range of $\mathrm{pH}$ was greater in Pearson, the extremes being 4.13 to 4.49 for Pearson and 4.22 to 4.38 for Simi. An attempt was made to test all samples at the same degree of ripeness, since ripeness is a governing factor in the $\mathrm{pH}$ value. Lo Coco (1945) found that generally the higher the total solids of tomatoes the higher the $\mathrm{pH}$ value.

Pectin content. Two samples of Pearson and Simi were tested for pectin content by a method supplied by Dr. H. H. Mottern, Director of Research, J. H. Heinz Company. Briefly, the method consists of slicing an equal weight of each sample into a tared container with a known amount of distilled water and "Calgon," a pentaphosphate, which is kept at a constant temperature of $85^{\circ} \mathrm{C}$ in a water bath. The tomatoes were sliced as they were used and slowly added to the container so as not to lower the temperature. The mixture was stirred gently to equalize the temperature but not hard enough to break the cells before the tomatoes were heated throughout. Upon removal from the water bath the samples were brought to their original weight by the addition of distilled water. A portion of each sample was filtered and the viscosity of the clear liquid tested in an Ostwald Fenske viscometer at $35^{\circ} \mathrm{C}$.

The pectin content based on the relative viscosity of two samples was 2.53 for Simi and 2.56 for Pearson. The difference is not significant.

Fleshiness. A method of flesh determination suggested by Dr. H. H. Mottern was applied to a sample of Pearson and Simi. This method consisted of weighing out a given amount of tomatoes, slicing them horizontally, and removing the seeds and interlocular material by means of a suction tube connected to a 1-liter suction flask which acted as a trap. The tomatoes were weighed again and the per cent of flesh calculated. Simi gave a value of 84.4 per cent flesh as compared to 76.5 per cent flesh for Pearson. These figures confirm the impression of greater fleshiness of Simi by inspection of cut fruits. Apparently the more fleshy condition is not associated with higher pectin content.

Color. It is important that concentrated processed tomatoes possess a deep red color since it is on the basis of color that the consumer judges the quality of these products. Simi, Pearson, and San Marzano tomatoes, grown on the southern California coastal plain, were compared for total color content. The first method used was that of Kramer and Smith (1946) with the exception that petroleum ether was used as a solvent instead of benzene. No water was added since the fresh fruit contained a considerable amount of juice. The pigments were extracted in petroleum ether and measured with a Beckman spectrophotometer in per cent of transmitted light at given wave lengths compared with that transmitted through the pure solvent, which was given a value of 100 . The greater the intensity of the pigments present the lower the percentage of transmittance.

The prepared solutions of the pigment extracts were measured at wave lengths from 430 to $500 \mathrm{~m} \mu$ at five-m $\mu$ increments, and the results plotted on a 


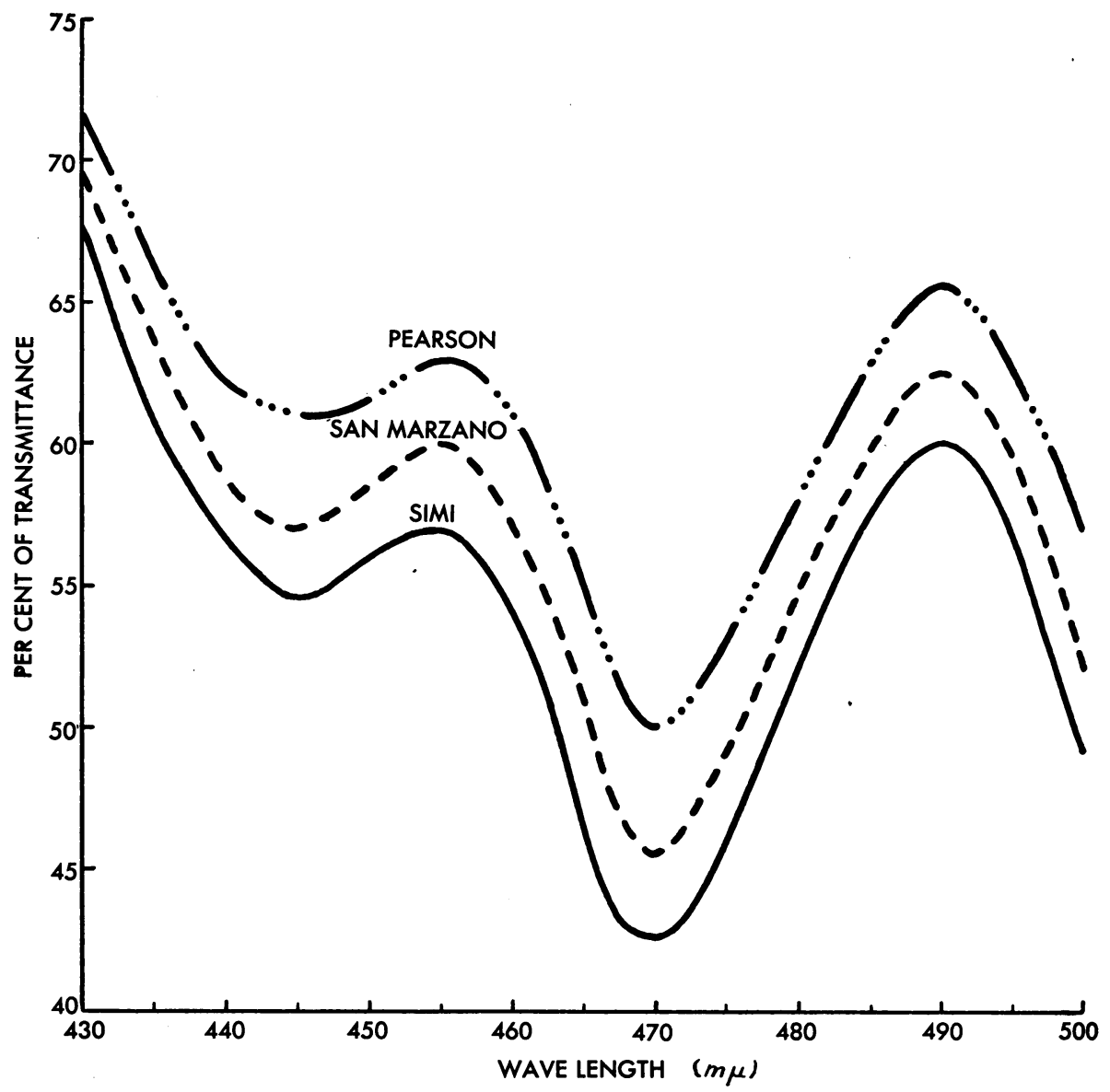

Fig. 3. Transmittance curves for petroleum ether extracts of Simi, Pearson, and San Marzano tomatoes.

graph. All tests were made on the same day the pigments were extracted from the tomatoes. At every wave length Simi gave lower values, indicating higher color intensity than Pearson or San Marzano. The close similarity of the curves (figure 3) suggests that the proportions of the main carotenoid constituents are the same.

A method of pigment extraction suggested by Dr. W. B. Davis ${ }^{8}$ was applied to three samples of Simi and Pearson tomatoes. It consisted of extracting the pigments in a Waring blendor with 1 per cent metaphosphoric acid. The extract was then mixed with filter-aid and filtered through sharkskin paper with a filter-aid pad on it. The pigments remained in the filter-aid and were removed by washing with acetone. They were then transferred to petroleum ether by means of a separatory funnel. The separation of the carotenes and

${ }^{6}$ For much helpful advice on colorimetric methods we are indebted to Dr. W. B. Davis, Chemist, Bureau of Agricultural and Industrial Chemistry, U. S. Department of Agriculture. 
lycopene from the remaining carotenoids followed the method of Zscheile and Porter (1947). The pigments were measured with a Beckman spectrophotometer at wave lengths of $436 \mathrm{~m} \mu$ and $502 \mathrm{~m} \mu$ for carotene and lycopene, respectively. In every case Simi gave a higher optical density and a lower percentage of light transmittance than Pearson, indicating a higher content of beta carotene and lycopene.

\section{SUMMARY}

The Simi variety is resistant to verticillium and fusarium wilts and has yielded well on infested soil on the coastal plain of southern California and in the Simi Valley.

No consistent difference in soluble solids content, measured by refractometer or by direct determination, has been found between Simi and Pearson. In 1948 and 1949 Simi was higher than Pearson but in 1950 the opposite was the case. Soluble solids estimates from the refractive index were generally lower than those obtained by drying. Both Pearson and Simi contained more soluble solids on the coastal plain than in interior valleys.

Simi was more fleshy than Pearson and clearly contained more carotenoid pigments according to spectrophotometer readings. These pigments are probably lycopene and beta carotene.

Viscosity (pectin) tests showed no significant difference between Simi and Pearson.

The Simi variety is recommended for trial on the southern California coastal plain and valleys near the coast. It was less fruitful than Pearson in the interior valleys. Simi is a good solid tomato, contains only a moderatesized white core, and is especially promising for processing into paste and other concentrates on account of its fleshiness and deep red color.

Fisher, W ALter D.

\section{LITERATURE CITED}

1947. Canning tomatoes. Situation in California 1947. Calif. Agr. Expt. Sta. Cir, 369:7. KRAMER, AMiHUd, and H. R. SMith

1946. Preliminary investigation on measurement of color in canned food. Food Res. $11: 14-30$.

Lo Coco, G.

1945. Composition of northern California tomatoes. Food Res. 10:114-21.

National Canners Association, Research Laboratory RePort.

1947. Refractive index, specific gravity, and solids relationships for tomato pulp and paste. Research Laboratory Rpt. No. 10566 C. September 26, 1947. National Canners Association Western Branch Laboratories, 322 Battery Street, San Francisco 11, California.

SAYwell, L. G., and W. V. Cruess.

1932. The composition of canning tomatoes. Calif. Agr. Expt. Sta. Bul. 545:8-13.

Shapovalov, M., and J. W. Lesley.

1940. Wilt resistance of the Riverside variety of tomato to both Fusarium and Verticillium wilts. Phytopath. $30(9): 760-68$.

Snyder, William C., H. N. HANsen, and Stephen Wilhelm.

1950. New hosts of Verticillium albo-atrum. U. S. Dept. Agr. Plant Dis. Reptr. 34(1): 26-27.

Zscheile, F. P., and J. W. Porter.

1947. Analytical methods for carotenes of Lycopersicon species and strains. Analyt. Chem. $19: 47-51$. 

The journal Hilgardia is published at irregular intervals, in volumes of about 600 pages. The number of issues per volume varies.

Subscriptions are not sold. The periodical is sent as published only to libraries, or to institutions in foreign countries having publications to offer in exchange.

You may obtain a single copy of any issue free, as long as the supply lasts; please request by volume and issue number from:

\section{Publications Office \\ College of Agriculture \\ Berkeley 4, California}

The limit to nonresidents of California is 10 separate issues on a single order. A list of the issues still available will be sent on request.

In order that the information in our publications may be more intelligible it is sometimes necessary to use trade names of products or equipment rather than complicated descriptive or chemical identifications. In so doing it is unavoidable in some cases that similar products which are on the market under other trade names may not be cited. No endorsement of named products is intended nor is criticism implied of similar products which are not mentioned. 


\section{CONTENTS}

Page

Simi, a Processing Tomato Resistant to Verticillium and Fusarium Wilts, by J. W. Lesley, John T. Middleton, and C. D. McCarty . . . . . . . . . 289 Introduction $\ldots \ldots \ldots \ldots \ldots \ldots \ldots \ldots \ldots \ldots \ldots \ldots \ldots . \ldots \ldots$

The Diseases . . . . . . . . . . . . . . . . . . . . . . 290

Infection of Tomato Plants $\ldots \ldots \ldots \ldots \ldots \ldots \ldots \ldots \ldots \ldots$

Occurrence of Strains in Verticillium albo-atrum . . . . . . . . . . 290

Development of the Variety $\ldots \ldots \ldots \ldots \ldots \ldots \ldots \ldots \ldots \ldots$

General Characteristics $\ldots \ldots \ldots \ldots \ldots \ldots \ldots \ldots \ldots \ldots \ldots \ldots . \ldots 292$

Horticultural Description . . . . . . . . . . . . . . . . 292

Composition ............................ 294

Summary $\ldots \ldots \ldots \ldots \ldots \ldots \ldots \ldots \ldots \ldots \ldots \ldots \ldots \ldots \ldots$

Literature Cited . . . . . . . . . . . . . . . . . . . . 299 